\title{
A Changing of the Guard at Human Genetics
}

(C) Springer-Verlag Berlin Heidelberg 2014

The occasion of an editorial succession is an excellent time not only to take stock of the journal's accomplishments and assess its current shape and scope, but also to contemplate its future direction. Tom Hudson, President and Director of the Ontario Institute for Cancer Research in Toronto, is stepping down at the end of 2014 as Co-Editor-in-Chief of Human Genetics, a role he has held since 2003. With a background spanning gene and genome mapping, the genetics of complex disease, cancer genomics, and a focus on translational research in the context of personalized medicine, Tom has been well placed to broaden the horizons of the journal at a time when the whole field of human genetics/genomics has been changing quite dramatically. Thus, during these last 12 years, the field of complex disease has rapidly moved from small exploratory studies with borderline results to massive genome-wide studies with validation. In parallel, the journal has steadily grown in terms of its scope, number of article submissions, the adoption of ever more stringent acceptance criteria, its core readership, article downloads and ISI Impact Factor. Human Genetics has become truly international, with a worldwide readership, article submissions from authors across the globe and a revamped Editorial Board that reflects the geographical reach of the journal. One novel feature in which Tom has played a leading role has been the advent of Special Issues, supervised by invited guest Editors, and covering topics as diverse as Personalized Medicine (2011), Biobanking (2011), Genetics of Substance Abuse and Addiction (2012), Genetic Epidemiology (2012) and Functional Characterization of Regulatory Elements in the Human Genome (2014).
Tom is standing down at the end of December 2014, so let us take this opportunity to express our heartfelt gratitude to him for his important contributions down the years. Moreover, we would also be remiss if we failed to recognize the bedrock of expert support that Catherine Mosco-Hudson provided as the journal's Managing Editor during Tom's term of service.

At the same time, let us welcome and introduce his replacement, Cynthia Morton from the Brigham and Women's Hospital/Harvard Medical School, Boston, past Editor of the American Journal of Human Genetics (2008-2013) and current President of the American Society of Human Genetics. Cynthia is a broadly trained human geneticist who is ABMG-certified in PhD Medical Genetics, Cytogenetics and Molecular Genetics and she has been the Director of Cytogenetics at Brigham and Women's Hospital since 1987. Her main research interests are uterine leiomyomata, hereditary hearing loss and cytogenetic approaches to gene discovery for developmental disorders. She brings with her a wealth of experience both in terms of an illustrious research career and in terms of editorial experience at the highest level.

In 2015 and beyond, David Cooper and Cynthia Morton very much look forward to continuing the success established under Drs. Cooper and Hudson, while developing new perspectives to encompass the exciting and dramatic developments occurring today in the field of human genetics.

$\begin{array}{ll}\text { David N. Cooper } & \text { Cynthia C. Morton } \\ \text { Cardiff } & \text { Boston }\end{array}$

